University of Nebraska - Lincoln

DigitalCommons@University of Nebraska - Lincoln

Faculty Publications from the Harold W. Manter Laboratory of Parasitology

2002

Phylogenetic Positions of the Bothitrematidae and

Neocalceostomatidae (Monopisthocotylean Monogeneans)

Inferred from 28S rDNA Sequences

Jean-Lou Justine

Richard Jovelin

Lassâd Neifar

Isabelle Mollaret

L.H. Susan Lim

See next page for additional authors

Follow this and additional works at: https://digitalcommons.unl.edu/parasitologyfacpubs

Part of the Parasitology Commons

This Article is brought to you for free and open access by the Parasitology, Harold W. Manter Laboratory of at DigitalCommons@University of Nebraska - Lincoln. It has been accepted for inclusion in Faculty Publications from the Harold W. Manter Laboratory of Parasitology by an authorized administrator of DigitalCommons@University of Nebraska - Lincoln. 
Authors

Jean-Lou Justine, Richard Jovelin, Lassâd Neifar, Isabelle Mollaret, L.H. Susan Lim, Sherman S. Hendrix, and Louis Euzet 


\title{
Phylogenetic Positions of the Bothitrematidae and Neocalceostomatidae (Monopisthocotylean Monogeneans) Inferred from 28S rDNA Sequences
}

\author{
Jean-Lou Justine,,${ }^{1,8}$ Richard Jovelin, ${ }^{1,2}$ Lassâd Neifar, ${ }^{3}$ Isabelle Mollaret,,${ }^{1,4}$ \\ L. H. Susan Lim, ${ }^{5}$ Sherman S. Hendrix, ${ }^{6}$ And Louis EuzeT ${ }^{7}$ \\ ${ }^{1}$ Laboratoire de Biologie Parasitaire, Protistologie, Helminthologie, Muséum National d'Histoire Naturelle, 61 \\ rue Buffon, F-75231 Paris Cedex 05, France (e-mail: justine@mnhn.fr), \\ ${ }^{2}$ Service de Systématique Moléculaire, Institut de Systématique, FR 1541, Muséum National d'Histoire \\ Naturelle, 43 rue Cuvier, F-75231 Paris, France, \\ ${ }^{3}$ Département de Biologie, Faculté des Sciences de Sfax, BP 802, 3018 Sfax, Tunisia, \\ ${ }^{4}$ University of Leeds, School of Biology, Leeds LS2 9JT, West Yorkshire, United Kingdom, \\ ${ }^{5}$ Institute of Biological Sciences, University of Malaya, 50603 Kuala Lumpur, Malaysia, \\ ${ }^{6}$ Department of Biology, Gettysburg College, Gettysburg, Pennsylvania 17325, U.S.A., and \\ ${ }^{7}$ Station Méditerranéenne de 1'Environnement Littoral, 1, Quai de la Daurade, 34200 Sète, France
}

ABSTRACT: A molecular phylogeny was inferred from newly obtained partial (D1 domain) 28S rDNA gene sequences of Bothitrema bothi (Bothitrematidae), Neocalceostoma sp. (Neocalceostomatidae), Bravohollisia sp. (Ancyrocephalidae), and other already available sequences of Ancyrocephalidae, Anoplodiscidae, Pseudodactylogyridae, and Sundanonchidae, with the Diplectanidae as outgroup. Bothitrema, Anoplodiscus, and Sundanonchus formed a very robust clade that was the sister group to a group that included all other species examined. In this latter group, Neocalceostoma and Thaparocleidus were basal to a clade in which the Ancyrocephalidae and Pseudodactylogyridae were sister groups. Molecular results that suggest inclusion of the families Bothitrematidae, Anoplodiscidae, and Sundanonchidae in the same group partially contradict a previous morphological analysis of Boeger and Kritsky in which the first 2 were placed in the Gyrodactylidea and the third in the Dactylogyridea.

KEY WORDS : Molecular phylogeny, rDNA sequences, Monogenea

The Monogenea has been the subject of several major molecular phylogenetic analyses in recent years. These have used sequences of the 28S rDNA D1 (Mollaret et al., 1997; Mollaret, Jamieson and Justine, 2000), D2 (Jovelin and Justine, 2001) or D3-D6 domains (Litvaitis and Rohde, 1999), 18S rDNA (Sinnappah et al., 2001), or a combination of $28 \mathrm{~S}$ and COI (Littlewood et al., 1997) or of $18 \mathrm{~S}$ and $28 \mathrm{~S}$ (Littlewood et al., 1998, 1999; Olson and Littlewood, 2002). The domain D1 of $28 \mathrm{~S}$ rDNA is poorly informative within the Polyopisthocotylea (Mollaret, Jamieson, and Justine, 2000), and better results were obtained with the D2 domain (Jovelin and Justine, 2001). In contrast, the Monopisthocotylea are relatively fast-evolving organisms, and the D1 domain used alone has revealed good resolving power within this group (Mollaret, Jamieson, and Justine, 2000; Mollaret, Lim, and Justine, 2000), although results concerning higher taxonomic rank obtained only

\footnotetext{
${ }^{8}$ Corresponding author.
}

with this domain are probably of limited value (Olson and Littlewood, 2002).

In the present article, we used the D1 domain to infer the phylogenetic positions of Bothitrema bothi (MacCallum, 1913) Price, 1936 (Bothitrematidae), a relatively obscure monogenean of the family Bothitrematidae, and Neocalceostoma sp., a member of the recently proposed family Neocalceostomatidae. A new sequence of $\mathrm{Bra}$ vohollisia sp. (Ancyrocephalidae) was also added to the database.

\section{Materials and Methods}

New sequences (accession numbers in Table 1) obtained for this study are from B. bothi from the windowpane Scophthalmus aquosus (Mitchill, 1815), New Jersey, U.S.A., collected by S.S.H., and from Bravohollisia sp. (Ancyrocephalidae) from a grunt Pomadasys hasta (Bloch, 1790), and Neocalceostoma sp. (Neocalceostomatidae) from the veined catfish Arius venosus (Valenciennes 1840), both collected by I.M. and L.H.S.L. in Malaysia. Nucleotide sequences data reported in the present article will be available in the GenBank database under accession numbers AF387508-A387510. Alignment data will be available 
Table 1. Taxonomic listing of monopisthocotylean monogeneans used in the analysis.

\begin{tabular}{|c|c|}
\hline Species & $\begin{array}{c}\text { GenBank accession } \\
\text { number }\end{array}$ \\
\hline \multicolumn{2}{|l|}{ Ancyrocephalidae } \\
\hline Tetrancistrum sp. & AF026114 \\
\hline Haliotrema chrysotaeniae Young, 1968 & AF026115 \\
\hline Ligophorus mugilinus (Hargis, 1955) Euzet et Suriano, 1977 & AF131710 \\
\hline Thaparocleidus siamensis (Lim, 1990) Lim, 1996 & AF218124 \\
\hline Cichlidogyrus sp. & AF218123 \\
\hline Pseudohaliotrema sphincteroporus Yamaguti, 1953 & AF382058 \\
\hline Bravohollisia sp. & AF387509* \\
\hline \multicolumn{2}{|l|}{ Pseudodactylogyridae } \\
\hline Pseudodactylogyrus sp. & AF382057 \\
\hline \multicolumn{2}{|l|}{ Neocalceostomatidae } \\
\hline Neocalceostoma sp. & AF387510* \\
\hline \multicolumn{2}{|l|}{ Anoplodiscidae } \\
\hline Anoplodiscus cirrusspiralis Roubal, Armitage et Rohde, 1983 & AF382060 \\
\hline \multicolumn{2}{|l|}{ Sundanonchidae } \\
\hline Sundanonchus micropeltis Lim et Furtado, 1985 & AF218122 \\
\hline \multicolumn{2}{|l|}{ Bothitrematidae } \\
\hline Bothitrema bothi (MacCallum, 1913) Price, 1936 & AF387508* \\
\hline \multicolumn{2}{|l|}{ Diplectanidae } \\
\hline Acleotrema sp. & AF026118 \\
\hline Furnestinia echeneis (Wagener, 1857) Euzet et Audoin, 1959 & AF131711 \\
\hline
\end{tabular}

* New sequences.

on request to the authors or from http://www.mnhn.fr/ $\mathrm{mnhn} / \mathrm{bpph} / \mathrm{Data} /$ IndexData.html.

Nucleotide sequence data reported were obtained by use of the methods detailed by Jovelin and Justine (2001) and only summarized herein. DNA extraction was performed on parasites kept in $90 \%$ ethanol by use of standard CTAB protocol (Winnepenninckx et al., 1993). The partial domain C1, full domain D1, and partial domain $\mathrm{C} 2$ of the $28 \mathrm{~S}$ rDNA were amplified by use of the universal primers $\mathrm{C}^{\prime}{ }^{\prime}\left(5^{\prime}\right.$-ACCCGCTGAATTTAAGCAT- $\left.3^{\prime}\right)$ and reverse C2 (5'CTCTCTYTYCAAAGTTCTTTTC-3'). PCR amplifications were processed with $5 \mu \mathrm{l}$ DMSO, $26.4 \mu \mathrm{lmix}$ dNTP at 6.6 $\mathrm{mM}, 60 \mathrm{pM}$ of each primer, $10 \mu \mathrm{l} 10 \times$ Buffer (Quantum), 3 U QBiotaq polymerase (Quantum, now Qbiogene, Inc., Illkirch, France), and $5 \mu 1$ template DNA made up to $50 \mu \mathrm{l}$ with water. PCR conditions were: hot start $\left(95^{\circ} \mathrm{C} / 4 \mathrm{~min}\right)$ followed by 35 cycles of $95^{\circ} \mathrm{C} /$ $30 \mathrm{sec}, 55^{\circ} \mathrm{C} / 30 \mathrm{sec}$, and $72^{\circ} / 30 \mathrm{sec}$. PCR products $(5$ $\mu 1)$ were first checked for size by gel electrophoresis with the molecular weight marker XIV (Boehringer Mannheim Corp., Meylan, France) on $1.5 \%$ agarose gel and were gel-purified on $1.5 \%$ agarose by use of the QIAquick PCR purification kit (Qiagen S.A., Courtaboeuf, France). The partial domain $\mathrm{C} 1$, full domain $\mathrm{D} 1$, and partial domain $\mathrm{C} 2$ were sequenced with an automated sequencer (Beckman Coulter, Inc., Palo Alto, California, U.S.A.) by use of the DNA CEQTM 2000 Kit from Beckman and following their concentrations under the following conditions: 40 cycles of $96^{\circ} \mathrm{C} / 40 \mathrm{sec}, 50^{\circ} \mathrm{C} / 40 \mathrm{sec}$, and $60^{\circ} \mathrm{C} / 4 \mathrm{~min}$. The primers used here allowed the entire sequence to be confirmed from both strands.

Previous alignments (Mollaret, Jamieson, and Justine, 2000; Mollaret, Lim, and Justine, 2000) were up- dated with the addition of our 3 new sequences and a selection of newly available sequences (Olson and Littlewood, 2002), with a total of 34 taxa of monopisthocotylean monogeneans. Sequence alignment was performed by eye with BioEdit (Hall, 1999) on a PC computer or SeqAl version 1a1 (Rambaut, 1996) on a Macintosh computer, by minimizing the insertion of gaps. Gaps were treated as a fifth base in the analysis. Base positions that could not be aligned unambiguously by eye were removed prior to phylogenetic analysis. Autapomorphies were removed from the matrix. Preliminary phylogenetic analyses revealed 3 monophyletic groups within the monopisthocotylean monogeneans, sustained by low bootstrap values: the Monocotylidae, the Capsalidae + Udonellidae, and a clade that contained the Ancyrocephalidae, Pseudodactylogyridae, Anoplodiscidae, Sundanonchidae, Bothitrematidae, Diplectanidae, and Neocalceostomatidae; the Diplectanidae were the sister group to the other taxa within this clade. In the present analysis, concentrating on the Bothitrematidae and closely related families (Table 1), the Diplectanidae were used as the outgroup for an analysis of the other taxa. This hypothesis is compatible, for the Ancyrocephalidae and other families, with a cladistic hypothesis based on morphology (Boeger and Kritsky, 2001) in which all these families belong to the monophyletic Dactylogyridea, but this does not extend to the Bothitrematidae and Anoplodiscidae. The hypothesis is compatible with an analysis based on $18 \mathrm{~S}$ rDNA, in which Anoplodiscus, Sundanonchus, Pseudodactylogyrus, and Pseudohaliotrema are in the same clade (Olson and Littlewood, 2002). In addition, the families included in the analysis all belong to the Monoaxonematidea Justine, 1991, a group characterized by the presence of spermatozoa with a single ax- 


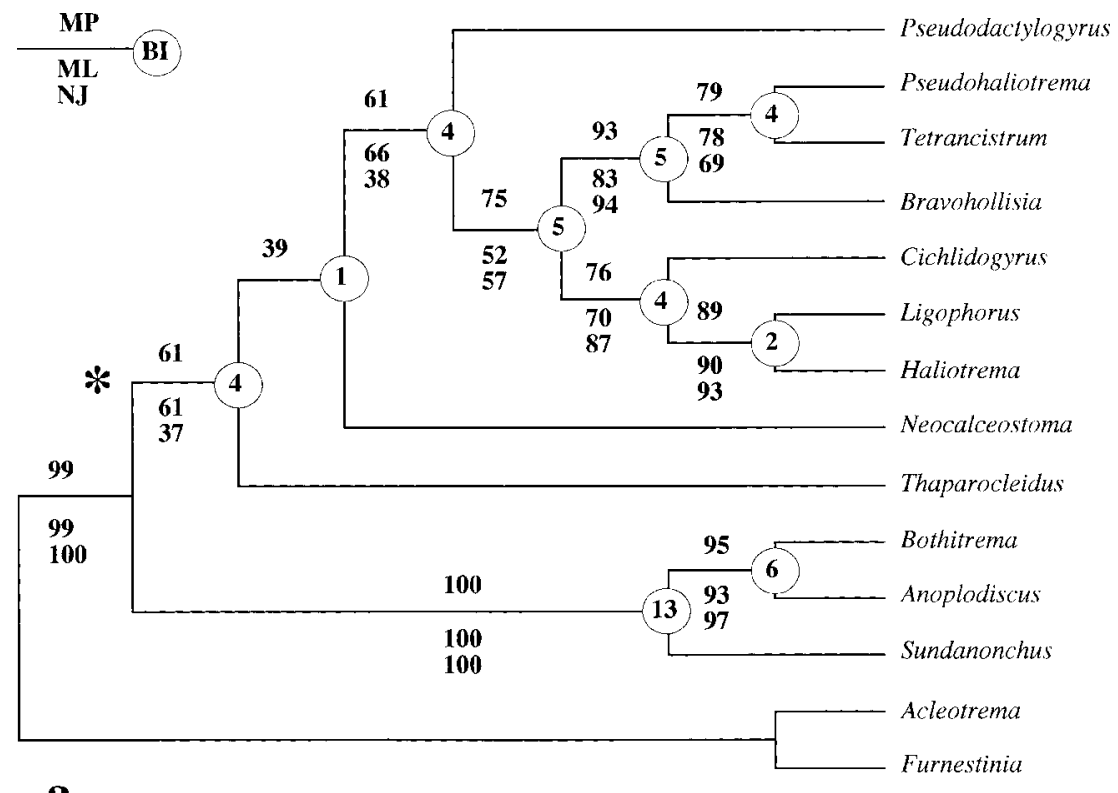

Pseudodactylogyridae

Ancyrocephalidae

Neocalceostomatidae

Ancylodiscoidinae

Bothitrematidae

Anoplodiscidae

Sundanonchidae

Diplectanidae (outgroup)

$\mathbf{a}$

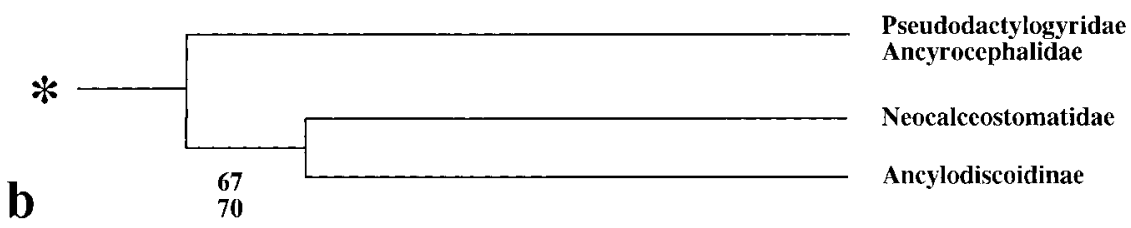

Figure 1. Phylogenetic trees of monopisthocotylean monogeneans. a. Single most parsimonious tree of the relationships between the Bothitrematidae, Neocalceostomatidae, and other families of monopisthocotylean monogeneans; the asterisk indicates different topology in ML tree. $b$. Single difference found in ML and NJ trees, with Neocalceostoma and Thaparocleidus united in the same clade. Above branch, MP bootstrap values; below branch, ML and NJ bootstrap values; nodes, Bremer indices.

oneme, but this does not apply to the Bothitrematidae and Neocalceostomatidae, for which the sperm ultrastructure is unknown (Justine, 1991, 2001).

Analyses were performed by use of PAUP* version $4.0 b 8$ (Swofford, 1998). Trees were obtained by maximum-parsimony (MP), neighbor-joining (NJ) (Saitou and Nei, 1987), and maximum-likelihood (ML) methods. For MP, trees were computed by branch-andbound. For NJ, distances were estimated by use of the Kimura-2-parameter model correcting for transition bias, all sites taken as evolving at the same rate. For ML, the model used was HKY85 (Hasegawa et al., 1985), accounting for transition/transversion ratios and base frequencies with all sites taken as evolving at the same rate and nucleotide frequencies estimated via ML. Nodal support was estimated with a bootstrap procedure (Felsenstein, 1985) with 400 replicates with branch-and-bound search and decay index (Bremer, 1994) for MP and a bootstrap procedure with 10,000 replicates for NJ and 200 replicates for ML. Decay index values were computed by use of Autodecay (Eriksson, 1997), and trees produced were drawn by use of Treeview (Page, 1996).

\section{Results}

A phylogenetic analysis was performed with use of the Ancyrocephalidae, Pseudodactylogyridae, Sundanonchidae, Bothitrematidae, and Neocalceostomatidae as the ingroup and the Diplectanidae as the outgroup. The matrix was composed of 14 taxa and 308 characters, among which 86 were informative. The branch-andbound search by MP led to a single tree, 330 steps in length, with a consistency index excluding uninformative characters of 0.54 . MP bootstrap analyses produced the same tree (Fig. 1a). A very robust clade included 3 species: $B$. bothi and A. cirrusspiralis, sister group of $S$. micropeltis. This clade was the sister group of all other species. Thaparocleidus siamensis was the next branch of the tree, then Neocalceostoma sp., then a clade in which Pseudodactylogyrus 
sp. was the sister group to a clade that included all the Ancyrocephalidae. The least robust node of the parsimony tree was the node that united Neocalceostoma and the Pseudodactylogyridae and Ancyrocephalidae; indeed, NJ and ML analyses and their bootstraps produced a slightly different tree (Fig. 1b), in which Neocalceostoma and Thaparocleidus were united in the same clade, with relatively high bootstraps; otherwise, the tree topology was the same.

\section{Discussion}

The classification adopted here for discussing our results uses family ranks for the Ancyrocephalidae and Pseudodactylogyridae. An alternative is to consider these, and others, as subfamilies of the Dactylogyridae (Kritsky and Boeger, 1989).

As expected, Bravohollisia was found within a clade that included Cichlidogyrus, Haliotrema, Ligophorus, Pseudohaliotrema, and Tetrancistrum. This clade corresponds to the Ancyrocephalidae, a "catch-all" group for many species, and detailed phylogenetic hypotheses within this group will need many more sequences. However, good support was found for a group that included all species belonging to the Ancyrocephalidae. Two clades were found within the family: 1 with Pseudohaliotrema, Tetrancistrum, and Bravohollisia, and 1 with Cichlidogyrus, Ligophorus, and Haliotrema; Cichlidogyrus sp. is the single species studied from freshwater fishes, whereas all other species are from marine fishes. Pseudodactylogyrus (Pseudodactylogyridae; see Le Brun et al., 1986) was found to be the sister group to the Ancyrocephalidae (Ancyrocephalinae).

Depending on the method used (MP vs. NJ or ML), a sister-group relationship or paraphyletic close relationships, were found between Thaparocleidus and Neocalceostoma. The family Neocalceostomatidae, to which Neocalceostoma belongs, was recently proposed to group several species previously included in the Calceostomatidae (Lim, 1995). Thaparocleidus has been classified within the Ancylodiscoidinae (Lim, 1990, 1996), a subfamily of the Ancyrocephalidae, and a recent morphological analysis supports raising the Ancylodiscoidinae to family status (Lim et al., 2001). Our results support the separation of the Ancylodiscoidinae from the Ancyrocephalidae (Ancyrocephalinae).

The main result of our analysis is the very robust sister-group relationships among the Bothitrematidae (B. bothi), Sundanonchidae (Sundanonchus micropeltis) and Anoplodiscidae (Anoplodiscus cirrusspiralis). The family Bothitrematidae has been classified within the Tetraonchidea (Bychowsky, 1961), and the family Sundanonchidae, after some initial instability, was also classified within the Tetraonchidea (Kritsky and Lim, 1995). The oncomiracidium of B. bothi (S.S.H., unpublished observations) has 2 pairs of eyes, with the posterior pair fused and a circle of 16 hooks in the haptor; the intestine is single in both the oncomiracidium and adult. Thus, the family Bothitrematidae shares the fused posterior eyes and single intestine with the Sundanonchidae and Tetraonchidae. Our molecular results support these relationships.

In a recent morphological analysis (Boeger and Kritsky, 2001), the Anoplodiscidae and Bothitrematidae were relatively close groups but were included within the Gyrodactylidea; the Sundanonchidae was, with the Tetraonchidae, within the Tetraonchidea. This morphological hypothesis is not compatible with our molecular results based on 28S D1 nor with an analysis based on $18 \mathrm{~S}$ complete sequences, in which Sundanonchus and Anoplodiscus are regularly found to be sister taxa (Olson and Littlewood, 2002). Inclusion of the Anoplodiscidae in the same group as Dactylogyridea revives the hypothesis of a monophyletic Monoaxonematidea, characterized by spermatozoa with a single axoneme (Justine, 1991). The sperm structure known as "Type 4," with a single axoneme and no microtubules (Justine, Lambert, and Mattei, 1985), is now known in the Anoplodiscidae, Diplectanidae, Ancyrocephalidae, Pseudodactylogyridae, Sundanonchidae, Tetraonchidae, Tetraonchoididae, Amphibdellatidae, and Calceostomatidae, but molecular data are lacking for the latter 4 families.

Recent comparative analyses of D1 and 18S sequences have shown that the domain D1 is not the best choice for resolving higher-rank phylogenetic relationships within the Monogenea (Olson and Littlewood, 2002). This is certainly true for the Polyopisthocotylea, in which domain D1 cannot resolve the higher branches of the tree (Jovelin and Justine, 2001; Mollaret, Jamieson, and Justine, 2000). However, the present study shows that such short sequences may be useful instruments for understanding relation- 
ships among at least certain groups within the Monopisthocotylea.

\section{Acknowledgments}

Peter Olson and Timothy Littlewood, The Natural History Museum, London, U. K., kindly communicated to us sequences and a manuscript in press.

\section{Literature Cited}

Boeger, W. A., and D. C. Kritsky. 2001. Phylogenetic relationships of the Monogenoidea. Pages 92-102 in D. T. J. Littlewood and R. A. Bray, eds. Interrelationships of the Platyhelminthes. Taylor and Francis, London, U.K. and New York, U.S.A.

Bremer, K. 1994. Branch support and tree stability. Cladistics 10:295-304.

Bychowsky, B. E. 1961. Monogenetic Trematodes: Their Systematics and Phylogeny. English translation edited by W. J. Hargis, Jr., American Institute of Biological Sciences, Washington, D.C., U.S.A. 627 pp.

Eriksson, T. 1997. AutoDecay version 2.9.10 (Hypercard stack distributed by the author). Botaniska Institutionen, Stockholm University, Stockholm, Sweden. Available at http://www.bergianska.se/ personal/TorstenE/.

Felsenstein, J. 1985. Confidence limits on phylogenies: an approach using the bootstrap. Evolution 39:783-791.

Hall, T. A. 1999. BioEdit: a user-friendly biological sequence alignment editor and analysis program for Windows 95/98/NT. Nucleic Acids Symposium Series 41:95-98.

Hasegawa, M., H. Kishino, and T. Yano. 1985. Dating of the human-ape splitting by a molecular clock of mitochondrial DNA. Journal of Molecular Evolution 22:32-38.

Jovelin, R., and J.-L. Justine. 2001. Phylogenetic relationships within the polyopisthocotylean monogeneans (Platyhelminthes) inferred from partial 28S rDNA sequences. International Journal for Parasitology 31:393-401.

Justine, J.-L. 1991. Cladistic study in the Monogenea (Platyhelminthes), based upon a parsimony analysis of spermiogenetic and spermatozoal ultrastructural characters. International Journal for Parasitology 21:821-838.

-2001. Spermatozoa as phylogenetic characters for the Platyhelminthes. Pages 231-238 in D. T. J. Littlewood and R. A. Bray, eds. Interrelationships of the Platyhelminthes, Taylor and Francis, London, U.K. and New York, U.S.A..

—, A. Lambert, and X. Mattei. 1985. Spermatozoan ultrastructure and phylogenetic relationships in the monogeneans (Platyhelminthes). International Journal for Parasitology 15:601-608.

Kritsky, D. C., and W. A. Boeger. 1989. The phylogenetic status of the Ancyrocephalidae Bychowsky, 1937 (Monogenea: Dactylogyroidea). Journal of Parasitology 75:207-211.

- and L. H. S. Lim. 1995. Phylogenetic posi- tion of Sundanonchidae (Platyhelminthes: Monogeneoidea: Dactylogyridea), with report of two species of Sundanonchus from toman, Channa micropeltes (Channiformes: Channidae), in Malaysia. Invertebrate Biology 114:285-295.

Le Brun, N., A. Lambert, and J.-L. Justine. 1986. Oncomiracidium, morphogenèse du hapteur et ultrastructure du spermatozoïde de Pseudodactylogyrus anguillae (Yin et Sproston, 1948) Gussev, 1965 (Monogenea, Monopisthocotylea, Pseudodactylogyridae n. fam.). Annales de Parasitologie Humaine et Comparée 61:273-284.

Lim, L. H. S. 1990. Silurodiscoides Gussev, 1961 (Monogenea: Ancyrocephalidae) from Pangasius sutchi Fowler, 1931 (Pangasiidae) cultured in Peninsular Malaysia. Raffles Bulletin of Zoology 38: 55-63.

- 1995. Neocalceostoma Tripathi, 1957 and Neocalceostomoides Kritsky, Mizelle \& Bilqees, 1978 (Monogenea: Neocalceostomatidae n. fam.) from ariid fishes of Peninsular Malaysia. Systematic Parasitology 30:141-151.

-1996. Thaparocleidus Jain, 1952, the senior synonym of Silurodiscoides Gussev, 1976 (Monogenea: Ancylodiscoidinae). Systematic Parasitology 35:207-215.

, T. A. Timofeeva, and D. I. Gibson. 2001. Dactylogyridean monogeneans of the siluriform fishes of the Old World. Systematic Parasitology 50:159-197.

Littlewood, D. T. J., K. Rohde, and K. A. Clough. 1997. Parasite speciation within or between host species?-Phylogenetic evidence from site-specific polystome monogeneans. International Journal for Parasitology 27:1289-1297.

$\longrightarrow, \ldots$, and $\longrightarrow$. 1998. The phylogenetic position of Udonella (Platyhelminthes). International Journal for Parasitology 28:1241-1250. , and -1999 . The interrelationships of all major groups of Platyhelminthes: phylogenetic evidence from morphology and molecules. Biological Journal of the Linnean Society 66:75-114.

Litvaitis, M. K., and K. Rohde. 1999. A molecular test of platyhelminth phylogeny: inferences from partial 28S rDNA sequences. Invertebrate Biology 118:42-56.

Mollaret, I., B. G. M. Jamieson, R. D. Adlard, A. Hugall, G. Lecointre, C. Chombard, and J.-L. Justine. 1997. Phylogenetic analysis of the Monogenea and their relationships with Digenea and Eucestoda inferred from 28S rDNA sequences. Molecular and Biochemical Parasitology 90:433438.

- $\longrightarrow$, and J.-L. Justine. 2000. Phylogeny of the Monopisthocotylea and Polyopisthocotylea (Platyhelminthes) inferred from 28S rDNA sequences. International Journal for Parasitology 30: 171-185.

, L. H. S. Lim, and J.-L. Justine. 2000. Phylogenetic position of the monogeneans Sundanonchus, Thaparocleidus and Cichlidogyrus inferred from 28S rDNA sequences. International Journal for Parasitology 30:659-662. 
Olson, P. D., and D. T. J. Littlewood. 2002. Phylogenetics of the Monogenea-evidence from a medley of molecules. International Journal for Parasitology. (In press.)

Page, R. D. M. 1996. Treeview: an application to display phylogenetic trees on personal computers. Computer Applications in the Biosciences 12: 357-358.

Rambaut, A. 1996. Se-Al, Sequence Alignment Editor. Version 1.0 alpha 1 . Software distributed by the Author, Department of Zoology, University of Oxford, Oxford, U.K.

Saitou, N., and M. Nei. 1987. The neighbor-joining method: a new method for reconstructing phylogenetic trees. Molecular Biology and Evolution 4: 406-425.
Sinnappah, N. D., L.-H. S. Lim, K. Rohde, R. Tinsley, R. Combes, and O. Verneau. 2001. A paedomorphic parasite associated with a neotenic amphibian host: phylogenetic evidence suggests a revised systematic position for Sphyranuridae within anuran and turtle polystomatoineans. Molecular Phylogenetics and Evolution 18:189-201.

Swofford, D. L. 1998. PAUP*. Phylogenetic Analysis Using Parsimony (*and Other Methods). Version 4. Sinauer Associates, Sunderland, Massachusetts, U.S.A.

Winnepenninckx, B., T. Backeljau, and R. D. De Wachter. 1993. Extraction of high molecular weight DNA from molluscs. Trends in Genetics 9:407. 